\title{
The effect of health education on the quality of life of postoperative patients with gastric cancer: a systematic review and meta-analysis
}

\author{
Gangmei Zhao', Yizhong Zhang', Chunbo Liu ${ }^{2}$ \\ ${ }^{1}$ Department of Gastrointestinal Surgery, Affiliated Hospital of Ningbo University School of Medicine, Ningbo, China; ${ }^{2}$ Hospital Dean's Office, \\ Affiliated Hospital of Ningbo University School of Medicine, Ningbo, China \\ Contributions: (I) Conception and design: G Zhao, C Liu; (II) Administrative support: Y Zhang; (III) Provision of study materials or patients: G \\ Zhao, Y Zhang; (IV) Collection and assembly of data: All authors; (V) Data analysis and interpretation: G Zhao, C Liu; (VI) Manuscript writing: All \\ authors; (VII) Final approval of manuscript: All authors. \\ Correspondence to: Chunbo Liu. Affiliated Hospital of Ningbo University School of Medicine, 247 Renmin Road, Jiangbei District, Ningbo 315020, \\ China. Email: zgm13957863491@163.com.
}

Background: Gastric cancer is one of the most common malignant tumors of the digestive tract
worldwide. This study aims to evaluate the effect of health education on gastric cancer patients' quality of
life after surgery.

Methods: China National Knowledge Infrastructure (CNKI) and Wanfang Data (WFD) were searched to obtain relevant studies. Key words: postoperative gastric cancer/health education/quality of life. A total of 88 subject-related literatures were retrieved, and 7 literatures that met the requirements were screened out and included in the meta-analysis research. Cochrane software Revman 5.0 was used to perform heterogeneity test, sensitivity analysis and pool analysis of the included literature.

Results: A total of 7 relevant studies meeting the requirements were included, involving 772 postoperative gastric cancer patients. According to the heterogeneity test results, the fixed effects model and the random effects model were adopted in this study. The results showed that the quality of life score of the health education group was higher than that of the control group $(\mathrm{P}<0.001)$, with an OR $(95 \% \mathrm{CI})$ value of 9.78 (8.59-10.99). The scores of physical function, role function, emotional function, cognitive function, and social function in the experimental group were higher than those in the control group $(\mathrm{P}<0.001)$, with $\mathrm{OR}$ (95\% CI) values of 8.13 (6.65-9.60), 8.99 (7.84-10.14), 9.84 (8.64-11.50), 6.55 (5.59-7.71), and 9.79 (8.5910.99), respectively.

Discussion: Health education can improve the overall health score of patients with gastric cancer after surgery. It can also improve the scores of physical function, role function, emotional function, cognitive function, and social function, and can significantly improve patients' quality of life.

Keywords: Health education; quality of life; meta-analysis; gastric carcinoma

Submitted Aug 06, 2021. Accepted for publication Oct 16, 2021.

doi: 10.21037/apm-21-2420

View this article at: https://dx.doi.org/10.21037/apm-21-2420

\section{Introduction}

Gastric cancer is the most common gastrointestinal tumor worldwide $(1,2)$. Epidemiological studies show that the incidence rate of gastric cancer has declined, but the mortality rate of patients has not changed significantly (3).
There are about 956,000 new cases of gastric cancer worldwide every year, and almost 801,000 deaths due to gastric cancer (4). The incidence rate and mortality rate of gastric cancer in China account for $45.1 \%$ and $42.7 \%$ (5) of worldwide rates, respectively. Radical resection is one of 
the main treatments for gastric cancer. The diagnosis and surgical treatment of malignant tumors are clear trigger events of the human stress response, which bring severe psychological burden to patients and reduce their quality of life. In addition, a series of social and behavioral factors, such as the cost of treatment and the demand for followup visits, have increased the psychological burden to a certain extent. At the same time as treating the disease itself, psychological intervention is one of the characteristics of individualized medical treatment. Reducing the psychological burden of patients and improving their quality of life are problems worthy of attention. As one of the psychological intervention methods, health education has been widely used in postoperative patients with gastric cancer $(6,7)$. Health education is an important part of clinical work and one of the prerequisites for patients to achieve self-management. Its clinical benefits are significantly better than conventional care. Health education can significantly improve clinical efficacy, reduce disease complications, and improve the quality of life of patients. With the development of modern medical concepts, the significance of health education has become increasingly prominent, and at the same time, patients' health education has increased day by day. Related domestic meta-analysis confirms that health education can improve the quality of life of patients with gastric cancer after surgery, but such meta-analysis is often limited to a specific surgical method, or only for patients with chemotherapy after gastric cancer and there is a certain time limitation. Our article includes relevant literature on the topic of health education for patients after gastric cancer surgery in recent years. And in this report, the quality of studies, in line with the corresponding standards, was screened, and a comprehensive systematic evaluation and analysis were carried out.

We present the following article in accordance with the PRISMA reporting checklist (available at https://dx.doi. org/10.21037/apm-21-2420).

\section{Methods}

\section{Literature search}

The main search databases of this study were China National Knowledge Infrastructure (CNKI) and Wanfang Data (WFD), which were searched from January 2000 to December 2020 using the key words postoperative gastric cancer, health education, quality of life.

\section{Inclusion and exclusion criteria}

The literature inclusion criteria were as follows: (I) postoperative patients with gastric cancer were randomly divided into the health education experimental group and routine nursing control group; (II) health education includes: disease process, symptom treatment, medication, risk factor treatment. Educational methods include: planned education, random education, written education, questionand-answer education, demonstration education, and point-to-face education. (III) research related articles were published in Chinese academic journals; (IV) the study was published from January 2000 to December 2020. The literature exclusion criteria were as follows: (I) the content of the study deviated from the results of this paper; (II) the study was published repeatedly; (III) documents were only used in academic conferences; (IV) the essential elements related to the study were incomplete; $(\mathrm{V})$ there was no control group. A total of 7 articles were included for metaanalysis (8-14).

\section{Data arrangement}

In this study, the content of the included articles was extracted. One researcher independently completed the content extraction, and 2 researchers independently checked this. The contents included the number of patients, the overall health score, the physical function score, the emotional function score, the cognitive function score, the social function score, and the role function score.

\section{Quality evaluation of studies}

According to the Cochrane systematic review system, this study evaluated the quality of studies from 3 aspects: randomization method, blinding method, and allocation concealment. The studies were divided into 3 levels: low bias, moderate bias, and severe bias. If all 3 levels of the study met the statistical requirements, it was judged as low bias. If one of the above 3 aspects was not described in the study, it was judged as moderate bias. If one or more of the above 3 aspects of the study were not used or did not meet the statistical requirements, it was judged as severe bias.

\section{Heterogeneity test and sensitivity analysis}

\section{Heterogeneity test}

The Chi-square test was used to test the heterogeneity 
between different studies. When the corrected $\mathrm{I}^{2}$ was more than $50 \%$, there was heterogeneity among different studies. When the corrected $\mathrm{I}^{2}$ was less than $50 \%$, there was no heterogeneity among different studies. When there was heterogeneity among the studies, the random effects model was used. The fixed effects model was used when there was no heterogeneity between studies.

\section{Sensitivity analysis}

This study adopts methods such as excluding low-quality research and using different model analysis to conduct sensitivity analysis. After excluding relevant literatures, the heterogeneity test was repeated, and the combined analysis model was selected. If there is no significant change in the results after the exclusion, the sensitivity is low and the results are credible. If the result changes significantly after the exclusion, it indicates that the sensitivity is high and the robustness of the result is low, and it indicates that there are important and potential bias factors related to the effect of intervention measures, and further clarifies the source of disputes.

\section{Statistical analysis}

All data in this study were analyzed by the Cochrane software RevMan 5.0. All data were measurement data, based on the mean \pm standard deviation, and were expressed in terms of odds ratio $(\mathrm{OR})$ and $95 \%$ confidence interval $(\mathrm{CI}) . \mathrm{P}<0.05$ indicated statistical significance.

\section{Results}

\section{Search results}

In this study, 88 related documents on the subject were retrieved through the databases. According to the standards mentioned above, 7 papers that met the requirements were selected and included in the meta-analysis. The studies were randomized controlled trials published in Chinese domestic journals. The number of subjects in the studies was 60-150, with 772 cases in total, as shown in Figure 1. The information and the number of patients included in the study are shown in Table 1 .

\section{Quality evaluation of the studies}

Among the 7 articles included in this study, all the randomization methods met the statistical requirements, but none described the allocation concealment and blinding method. All included articles were evaluated as moderate bias.

Comparison of the total bealth score between the experimental group with postoperative health education for gastric cancer and the control group with standard care after gastric cancer surgery

A total of 692 patients from 6 studies were included, and the heterogeneity test results were $\chi^{2}=26.30, \mathrm{P}<0.001$, and $\mathrm{I}^{2}=81 \%$, which indicated that there was heterogeneity among the 6 studies. The random effects model combined the data. The results of the meta-analysis showed that the OR $(95 \% \mathrm{CI})$ value of difference between the total health score of the experimental group and the control group was 9.79 (8.59-10.99), and there was a significant difference between the 2 groups, with $\mathrm{Z}=15.98(\mathrm{P}<0.001)$ (Figure 2). The funnel plot showed that most of the points were within the confidence interval, showing an inverted funnel plot indicating no publication bias. Therefore, the research results were reliable, as shown in Figure 3.

\section{Comparison of the scores of physical function between the experimental group with postoperative health education for gastric cancer and the control group with standard care after gastric cancer surgery}

A total of 510 patients from 5 studies were included. The heterogeneity test results were $\chi^{2}=6.60, \mathrm{P}=0.16$, and $\mathrm{I}^{2}=39 \%$, indicating that there was no heterogeneity among the 5 studies. The fixed effects model was used to merge the data. The meta-analysis results showed that the OR ( $95 \% \mathrm{CI}$ ) value of difference between the physical function score of the experimental group with health education and the control group with standard care was 8.13 (6.65-9.60). There was a significant difference between the 2 groups, with $\mathrm{Z}=10.78(\mathrm{P}<0.001)$ (Figure 4). The funnel plot showed that each point was within the confidence interval, showing an inverted funnel plot indicating no publication bias. Thus, the research results were reliable, as shown in Figure 5.

\section{Comparison of the role function scores between the experimental group with postoperative bealth education for gastric cancer and the control group with standard care after gastric cancer surgery}

A total of 510 patients in 5 studies were included, and the 
Identification of studies via databases

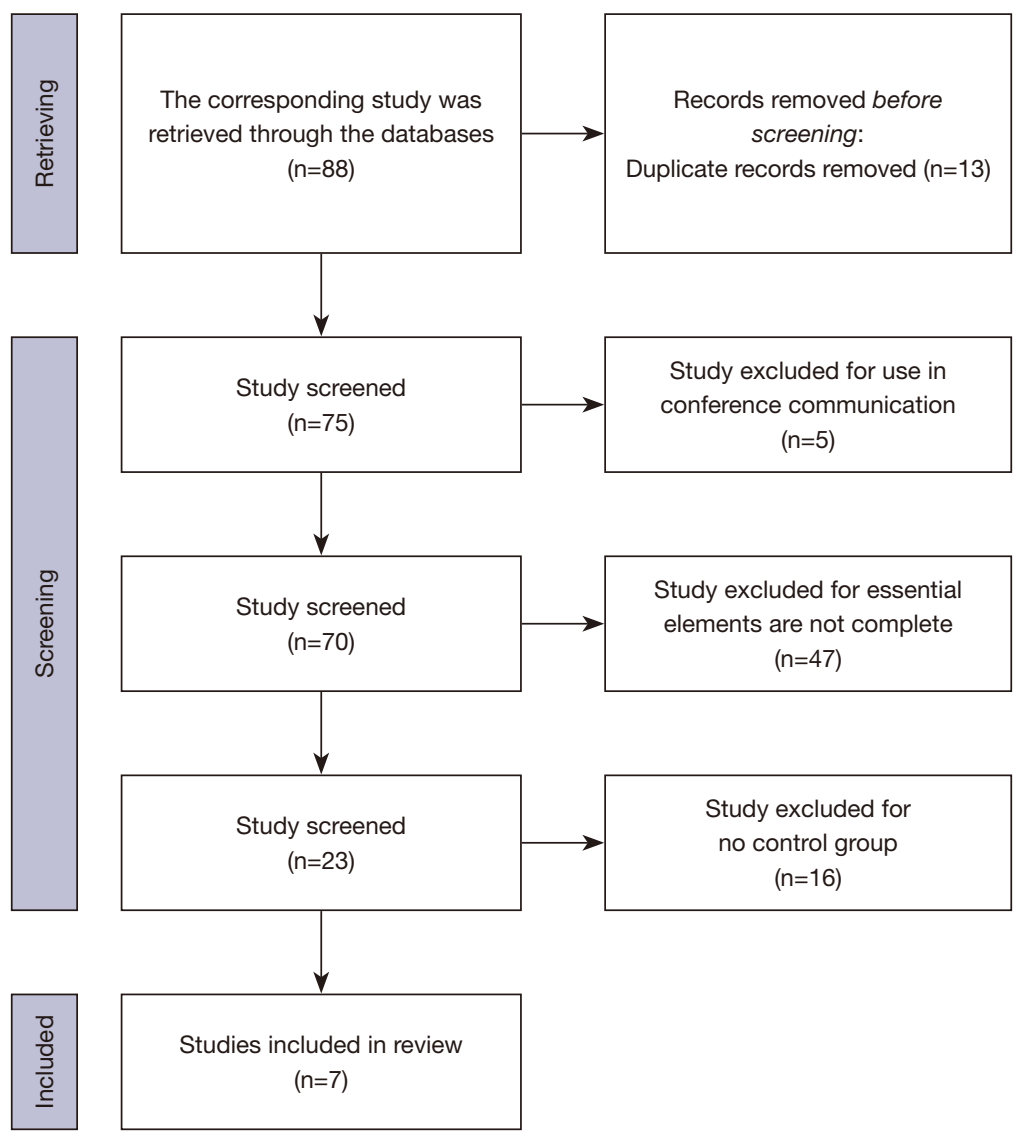

Figure 1 Flow chart depicting search strategy for the systematic review.

Table 1 Clinical baseline information of all the included patients

\begin{tabular}{|c|c|c|c|c|c|c|c|}
\hline \multirow{2}{*}{ Study } & \multirow{2}{*}{$\begin{array}{l}\text { Study } \\
\text { design }\end{array}$} & \multicolumn{2}{|c|}{ Treatment } & \multicolumn{2}{|c|}{ No. of patients } & \multicolumn{2}{|c|}{$\begin{array}{l}\text { Gender of patients } \\
\text { (male/female) }\end{array}$} \\
\hline & & Experimental & Control & Experimental & Control & Experimental & Control \\
\hline Wang 2004 & $\mathrm{RCT}$ & Health education intervention & Routine nursing mode & 56 & 56 & $29 / 27$ & $29 / 27$ \\
\hline Liu 2013 & $\mathrm{RCT}$ & Health education intervention & Routine nursing mode & 30 & 30 & $25 / 5$ & $23 / 7$ \\
\hline Lv 2016 & $\mathrm{RCT}$ & Health education intervention & Routine nursing mode & 60 & 60 & $35 / 25$ & $36 / 24$ \\
\hline Wang 2019 & $\mathrm{RCT}$ & Health education intervention & Routine nursing mode & 75 & 75 & $41 / 34$ & $39 / 36$ \\
\hline Liu 2014 & $\mathrm{RCT}$ & Health education intervention & Routine nursing mode & 75 & 75 & $43 / 32$ & $44 / 31$ \\
\hline
\end{tabular}




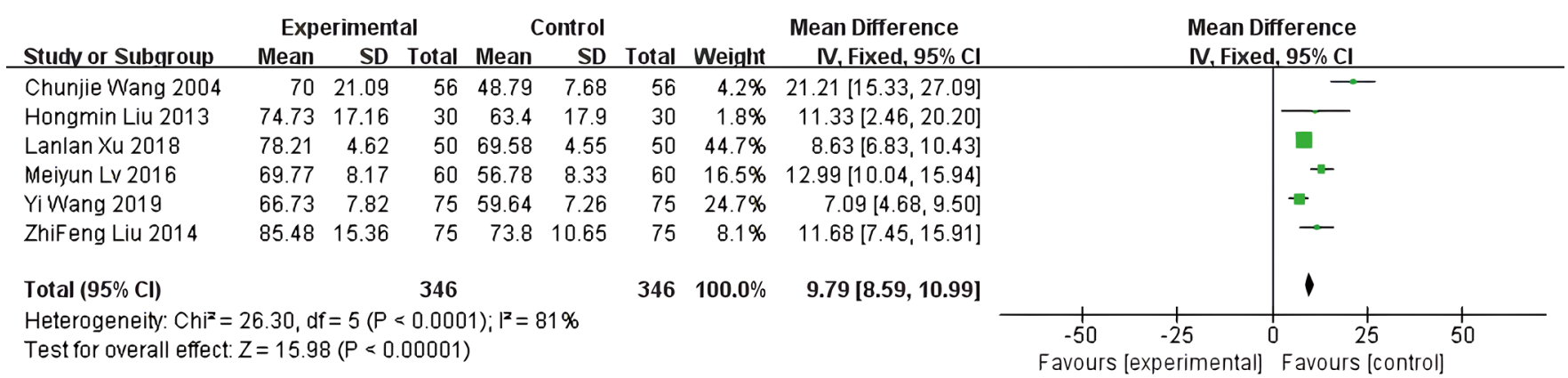

Figure 2 Comparison of the total health score between the experimental group with postoperative health education for gastric cancer and the control group with standard care after gastric cancer surgery. SD, standard deviation.

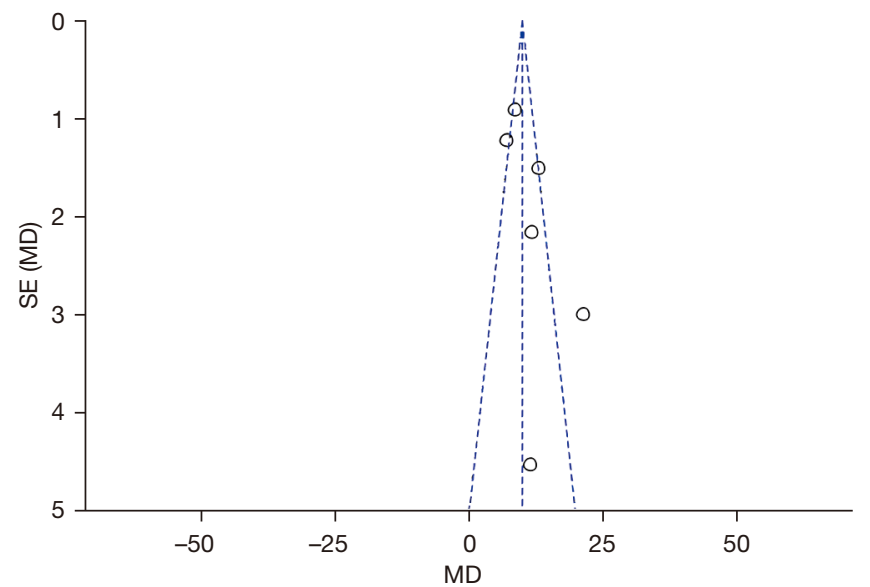

Figure 3 Funnel plot of the total health score between the experimental group and the control group after gastric cancer surgery. SE, standard error; MD, mean difference.

heterogeneity test results were $\chi^{2}=48.35, \mathrm{P}<0.001$, and $\mathrm{I}^{2}=92 \%$, indicating that there was heterogeneity among the 5 studies. The data were combined by the random effects model. The results of the meta-analysis showed that the OR ( $95 \% \mathrm{CI}$ ) value of difference between the postoperative role function score in the health education experimental group and the routine nursing control group was 8.99 (7.84-10.14), and there was a significant difference between the 2 groups, with $\mathrm{Z}=15.34$ ( $\mathrm{P}<0.001)$ (Figure 6). The funnel plot showed that most points were within the confidence interval, showing an inverted funnel plot indicating no publication bias. The research results were reliable, as shown in Figure 7.
Comparison of the scores of emotional function between the experimental group with postoperative health education for gastric cancer and the control group with standard care after gastric cancer surgery

A total of 510 patients from 5 studies were included, and the heterogeneity test results were $\chi^{2}=17.94, \mathrm{P}=0.002$, and $\mathrm{I}^{2}=77 \%$, which indicated that there was heterogeneity among the 5 studies. The data were combined by the random effects model. The results of the meta-analysis showed that the OR $(95 \% \mathrm{CI})$ value of difference between the postoperative emotional function score in the health education experimental group and the routine nursing control group was 9.84 (8.64-11.05), and there was a significant difference between the 2 groups $(Z=16.06$, $\mathrm{P}<0.001$ ) (Figure 8). The funnel plot showed that most points were within the confidence interval, showing an inverted funnel plot indicating publication bias. Therefore, the research results were reliable, as shown in Figure 9.

\section{Comparison of cognitive function scores between the experimental group with postoperative health education for gastric cancer and the control group with standard care after gastric cancer surgery}

A total of 510 patients from 5 studies were included. The heterogeneity test results were $\chi^{2}=20.94, \mathrm{P}<0.001$, and $\mathrm{I}^{2}=81 \%$, which indicated that there was heterogeneity among the 5 studies. The data were combined by the random effects model. The results of the meta-analysis showed that the OR $(95 \% \mathrm{CI})$ value of difference between 


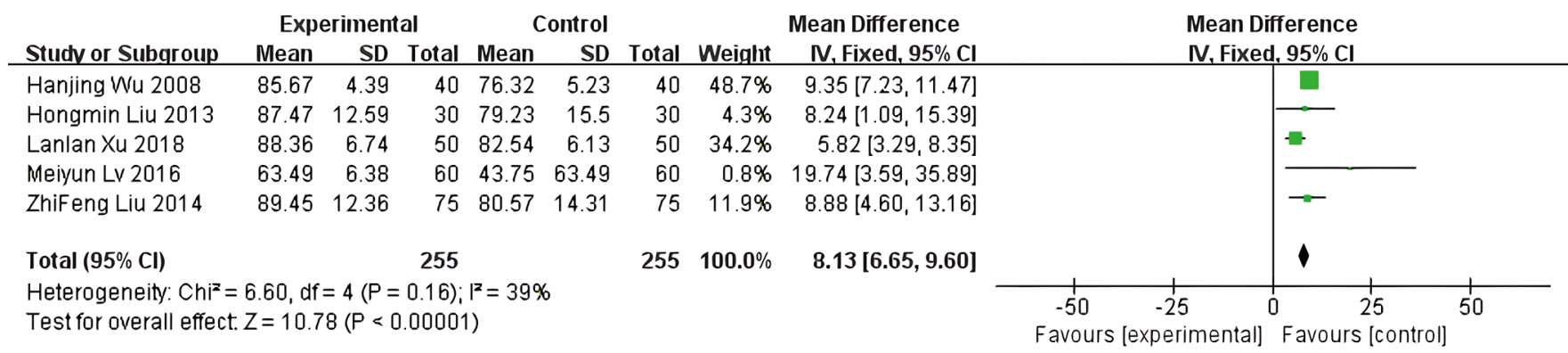

Figure 4 Comparative analysis of the physical function score between the experimental group with health education and the control group with standard care after gastric cancer surgery. SD, standard deviation.

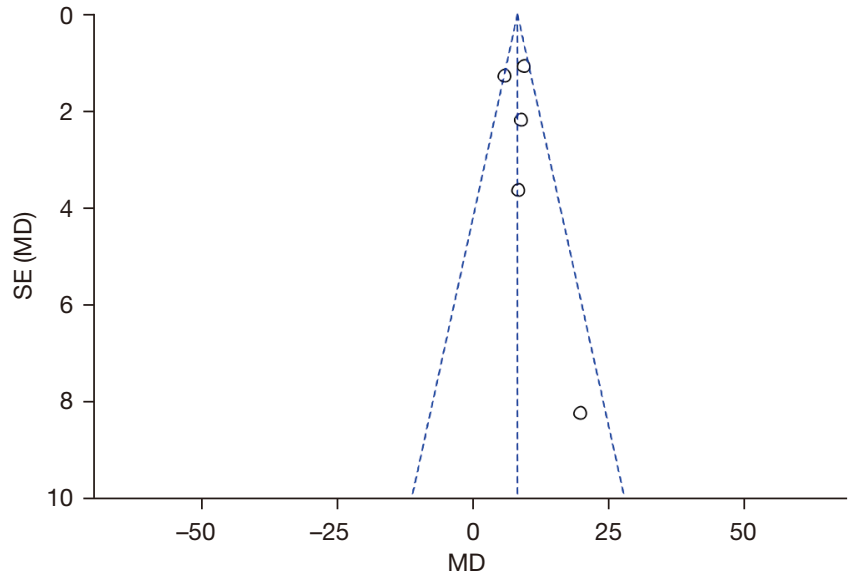

Figure 5 Funnel plot of the physical function score between the experimental group and the control group of gastric cancer patients after surgery. SE, standard error; MD, mean difference. the postoperative cognitive function score in the health education experimental group and the routine nursing control group was $6.65(5.59-7.71)$, and there was a significant difference between the 2 groups, with $Z=12.31$ $(\mathrm{P}<0.001)$ (Figure 10). The funnel plot showed that most points were within the confidence interval, showing an inverted funnel plot without publication bias. The research results were reliable, as shown in Figure 11.

\section{Comparison of the social function scores between the} experimental group with postoperative health education for gastric cancer and the control group with routine nursing care after surgery

A total of 510 patients from 5 studies were included, and the heterogeneity test results were $\chi^{2}=65.34, \mathrm{P}<0.001$, and

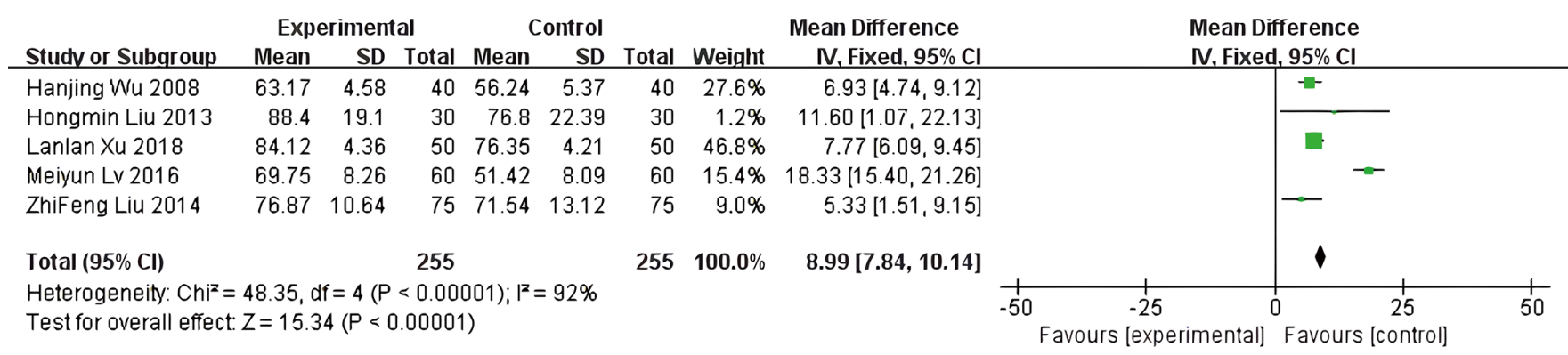

Figure 6 Comparative analysis of the role function score between the experimental group and the control group after gastric cancer surgery. SD, standard deviation. 
$\mathrm{I}^{2}=94 \%$, indicating that there was heterogeneity among the 5 studies. The data were combined using the random effects model. The results of the meta-analysis showed that there was no significant difference between the 5 studies. The OR (95\% CI) value of difference between the postoperative social function score in the health education experimental group and the routine nursing control group was $6.96(5.87-8.05)$, and the difference between the 2 groups was statistically significant, with $\mathrm{Z}=12.50(\mathrm{P}<0.001)$ (Figure 12). The funnel plot showed that each point was scattered, and there was a certain publication bias, as shown in Figure 13.

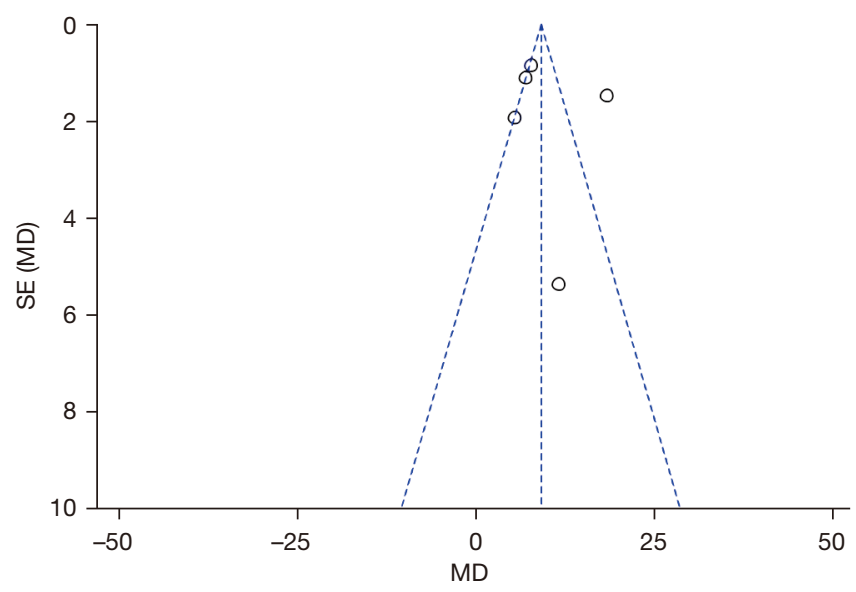

Figure 7 Funnel plot of the role function score between the experimental group and the control group of gastric cancer patients after surgery. SE, standard error; $\mathrm{MD}$, mean difference.

\section{Discussion}

Gastric cancer is one of the most common malignant tumors, and the incidence rate and mortality rate are relatively high $(15,16)$. In addition to the impact of the disease itself on the human body, the diagnosis, treatment, monitoring, and related economic costs of gastric cancer can pose a serious psychological burden to patients and affect their quality of life. This psychological burden may also affect the therapeutic effect to a certain extent. With the progress of social civilization, medical treatment is not limited to the disease itself. Psychological intervention, including health education and humanistic care, has received attention and has gradually been integrated into disease treatment. Health education refers to establishing patients' correct understanding of the disease to better cooperate with the treatment and guide patients to develop beneficial daily living habits $(17,18)$. Some studies have put forward the mode of combining health promotion, health education, and patient education. Lichtenstein believed that traditional patient education focused on the process of disease (18). Today's concept should emphasize disease in people's lives and focus on the non-medical factors that affect the disease (18). It is of great clinical significance to explore the influence of health education on gastric cancer patients' quality of life after surgery. In this paper, a meta-analysis was used to analyze this topic. This study focuses on the study of domestic gastric cancer patients after surgery, so the English database is excluded, and CNKI and WFD are selected for literature screening more specifically.

The results showed that health education could

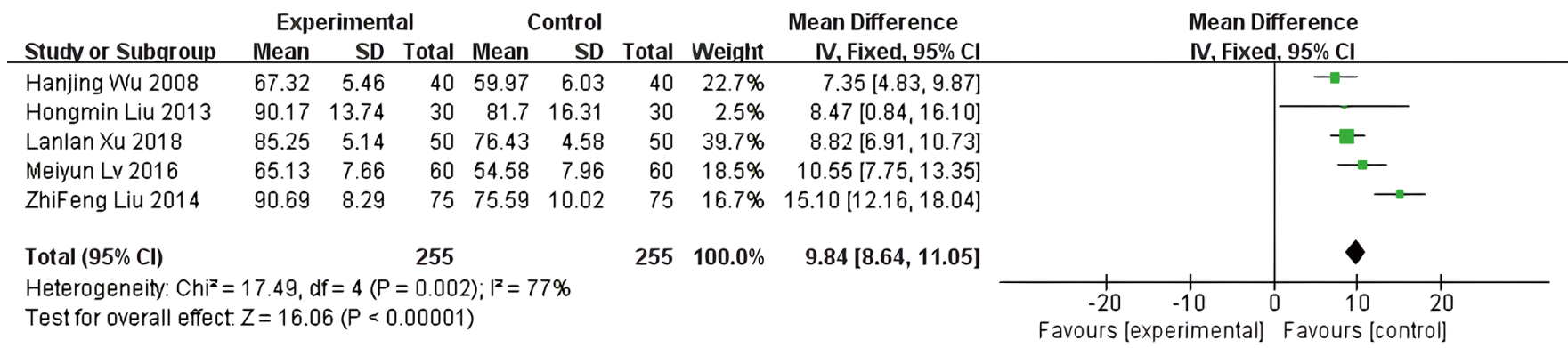

Figure 8 Comparative analysis of the emotional function score between the experimental group with health education and the control group with standard care after gastric cancer surgery. SE, standard error. 


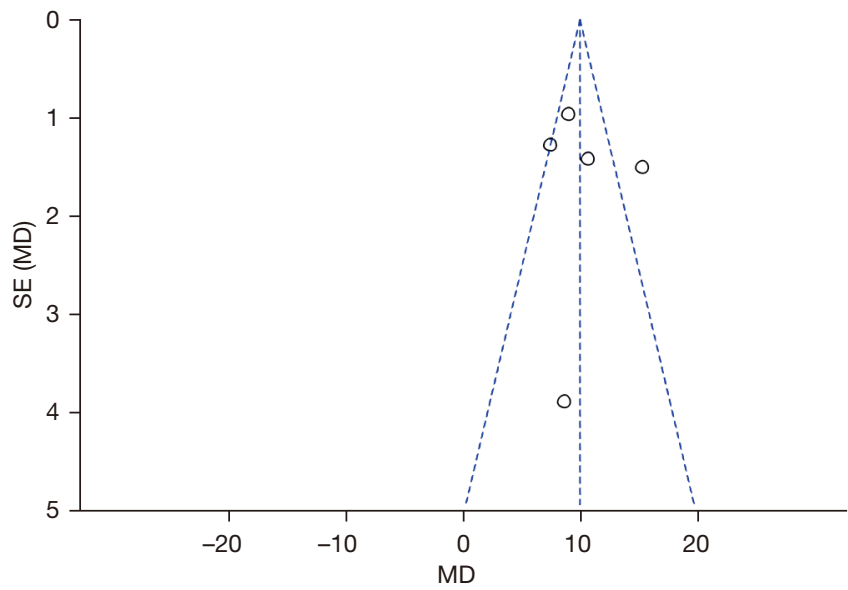

Figure 9 Funnel plot of the emotional function score in the experimental group and the control group after gastric cancer surgery. SE, standard error; MD, mean difference.

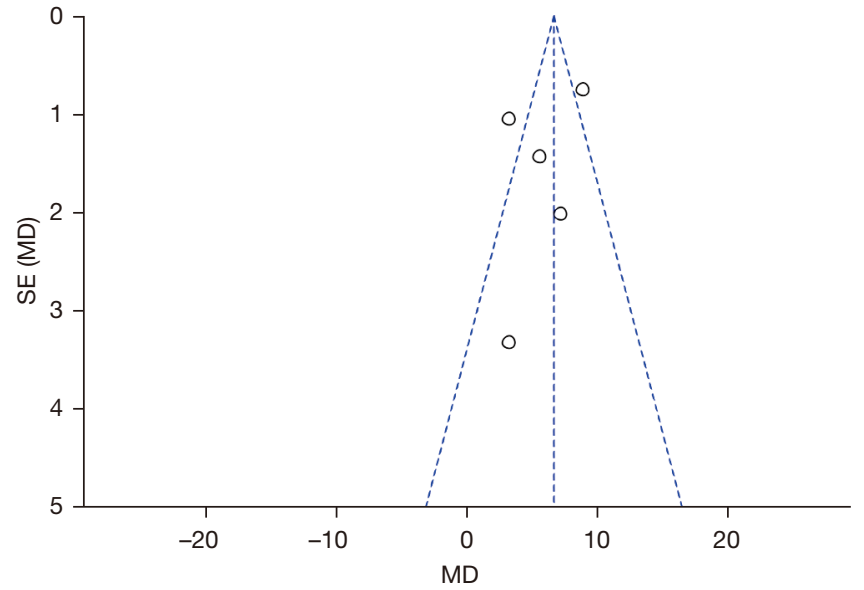

Figure 11 Funnel plot of the cognitive function score in the experimental group and the control group after gastric cancer surgery. SE, standard error; MD, mean difference.

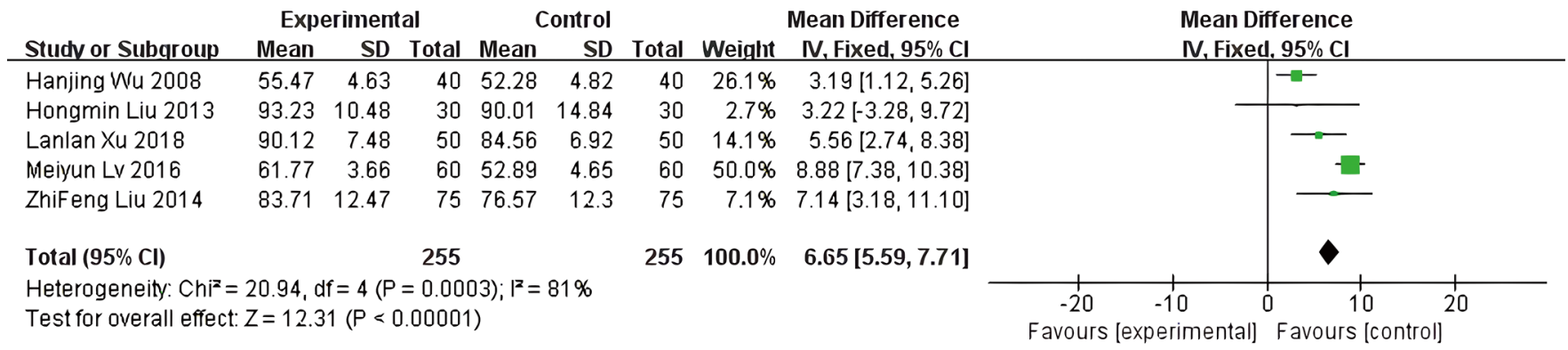

Figure 10 Comparative analysis of the cognitive function score between the experimental group with postoperative health education and the control group with standard care after gastric cancer surgery. SE, standard error.

significantly improve the health score, physical function score, role function score, emotional function score, cognitive function score, and social function score of patients after a gastric cancer surgery. Therefore, we believe that health education can significantly improve gastric cancer patients' quality of life after surgery. Health education can help patients understand the disease and reduce the psychological burden. Health education can also guide patients to improve their unhealthy lifestyles, benefit from healthy behaviors, and improve their quality of life, which may be the reasons for this result. It is worth noting that some studies have pointed out that health education has a weak impact on social function, including the economic burden of treatment costs, and cannot improve the social role of patients. However, we believe that social functions include communication, integration, guidance, inheritance, and development. The importance of health education has become increasingly prominent. Improving the level of health education can be used as a powerful supplement to medical methods to improve the effectiveness of treatment and the quality of medical treatment. To improve health education, attention should be paid to the following aspects. The first is to emphasize the significance of health education for medical staff, and conduct health education and training for medical staff. The second is to adopt more flexible and changeable methods for health education, such as joint video images, using mainstream communication software to build a platform, and joint health belief models. Finally, communicate with patients on an equal footing, discuss together, and pay attention to wording, posture, and attitude in the process of health education.

There are some deficiencies in this study. There are few 


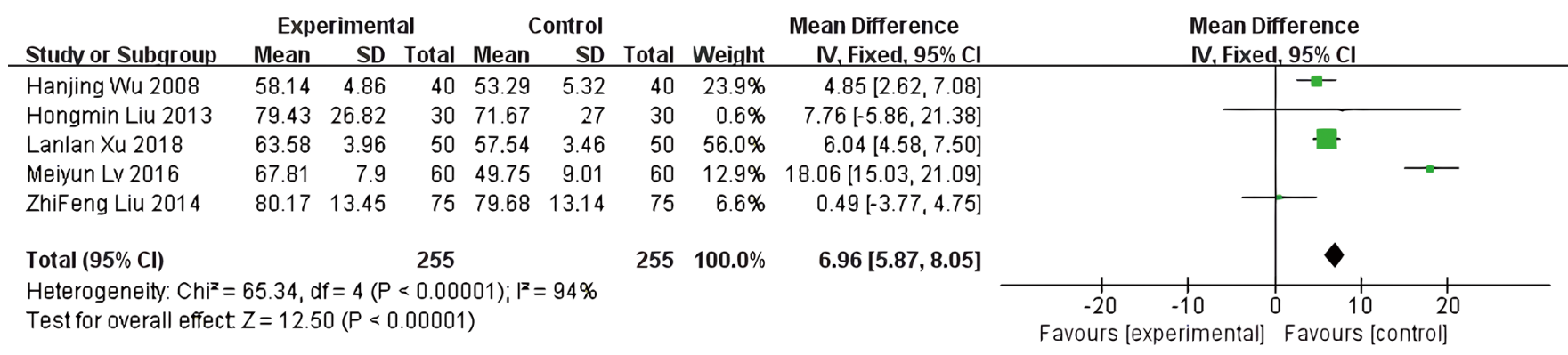

Figure 12 Comparative analysis of the social function score between the experimental group and the control group after gastric cancer surgery. SE, standard error.

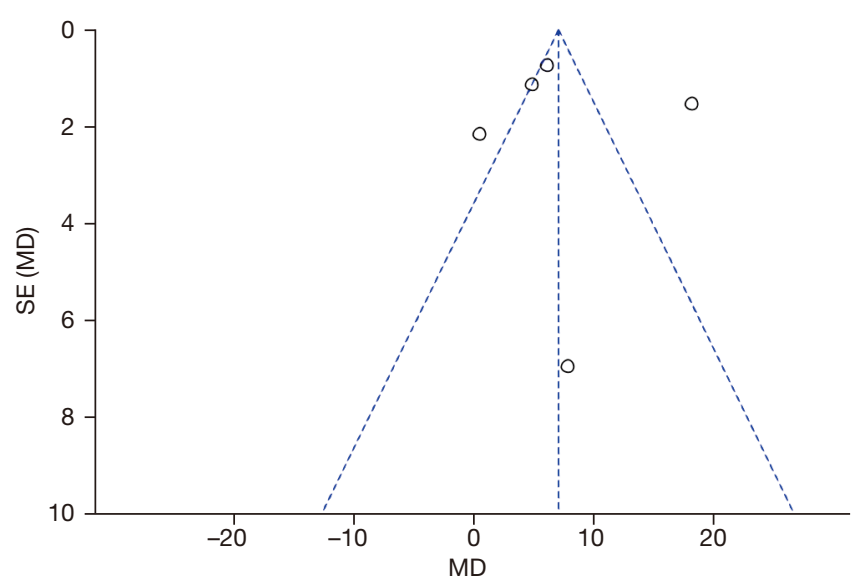

Figure 13 Funnel plot of the social function score in the experimental group and the control group after gastric cancer surgery. SE, standard error; MD, mean difference.

reports regarding the effect of health education on gastric cancer patients' quality of life after surgery. Therefore, this study cannot include more studies for comprehensive analysis, which affects the reliability of the results to a certain extent. This study only focused on improving quality of life, the incidence of postoperative complications, and the change in treatment compliance worthy of attention.

In conclusion, health education can improve the total health, physical function, role function, emotional function, cognitive function, and social function scores of patients with gastric cancer after surgery, and can significantly improve their quality of life.

\section{Acknowledgments}

Funding: None.

\section{Footnote}

Reporting Checklist: The authors have completed the PRISMA reporting checklist. Available at https://dx.doi. org/10.21037/apm-21-2420

Conflicts of Interest: All authors have completed the ICMJE uniform disclosure form (available at https://dx.doi. org/10.21037/apm-21-2420). The authors have no conflicts of interest to declare.

Ethical Statement: The authors are accountable for all aspects of the work in ensuring that questions related to the accuracy or integrity of any part of the work are appropriately investigated and resolved.

Open Access Statement: This is an Open Access article distributed in accordance with the Creative Commons Attribution-NonCommercial-NoDerivs 4.0 International License (CC BY-NC-ND 4.0), which permits the noncommercial replication and distribution of the article with the strict proviso that no changes or edits are made and the original work is properly cited (including links to both the formal publication through the relevant DOI and the license). See: https://creativecommons.org/licenses/by-nc-nd/4.0/.

\section{References}

1. Kivilaakso E. Gastric carcinoma. Scand J Surg 2006;95:215-7.

2. Ben Kridis W, Marrekchi G, Mzali R, et al. Prognostic factors in metastatic gastric carcinoma. Exp Oncol 2019;41:173-5.

3. Siegel RL, Miller KD, Jemal A. Cancer statistics, 2016. CA Cancer J Clin 2016;66:7-30. 
4. Siegel RL, Miller KD, Jemal A. Cancer statistics, 2018. CA Cancer J Clin 2018;68:7-30.

5. Cao M, Li H, Sun D, et al. Epidemiological trends of gastric cancer in China from to 2019. Chinese Journal of Digestive Surgery 2021;20:102-9.

6. Gao Q, Li H, Zou Y, et al. Effectiveness of a comprehensive post-operative health education program in improving quality of life after gastric cancer surgery. Ann Palliat Med 2020;9:921-6.

7. He Y, Shen S, Li J, et al. Effect of health education on anxiety state and clinical compliance of patients with gastric cancer undergoing postoperative chemotherapy. Journal of Hebei Medical University 2020;41:99-102.

8. Liu Z. Effect of health education on postoperative psychological status and quality of life of patients with gastric cancer. International Journal of Nursing ;33:618-20.

9. Wu H. Influence of Health Education Intervention on Cancer-related Fatigue and Quality of Life in Gastric Cancer Patients. Nursing Journal of Chinese People Liberation Army 2008;25:9-11.

10. Lv M. Influence of health education and psychological nursing on the quality of life of patients underwent laparoscopic radical gastrostomy. Clinical Research and Practice 2016;1:152-3.

11. Xu L, Xiao J, Xu P. Effects of humanistic nursing mode combined with situational experiential health education

Cite this article as: Zhao G, Zhang Y, Liu C. The effect of health education on the quality of life of postoperative patients with gastric cancer: a systematic review and meta-analysis. Ann Palliat Med 2021;10(10):10633-10642. doi: 10.21037/apm-21-2420 on negative psychology, treatment compliance and quality of life of patients undergoing radical gastrectomy. World Chinese Journal of Digestion 2018;26:729-34.

12. Liu H, Zhao Y, Zhan H, et al. Influence of implementation of continuous health education on recent quality of life and physiological indexes of gastric cancer patients after total gastrectomy. Chinese Nursing Research 2013;27:1262-4.

13. Wang C. Relationship between quality of life and health education intervention in patients undergoing total gastrectomy. Chinese Journal of Clinical Rehabilitation 2004;8:6489.

14. Wang Y, Zeng X, Xu Q. Effect of mental resilience training combined with staged health education on mental state, coping style and quality of life of patients undergoing radical gastrectomy. Chinese Journal of Health Psychology 2009;27:1774-8.

15. Boullosa PE, Varela AB, Otero JP, et al. Calcified gastric carcinoma. Rev Esp Enferm Dig 2010;102:669.

16. Phan AT, Ajani JA. Gastric carcinoma. Curr Oncol Rep 2004;6:192-8.

17. Schrieber L, Colley M. Patient education. Best Pract Res Clin Rheumatol 2004;18:465-76.

18. Lichtenstein GR. Patient Education. Gastroenterol Hepatol (N Y) 2015;11:360.

(English Language Editor: C. Betlzar) 